\title{
MARINE FOULING AND ITS PREVENTION
}

PREPARED FOR

BUREAU OF SHIPS, NAVY DEPARTMENT

BY

WOODS HOLE OCEANOGRAPHIG INSTITUTION

WOODS HOLE, MASSAGHUSETTS

DATA LBRAPY

WOODS HOLE OCEANOGRAPIDIC INSTITUTHOW

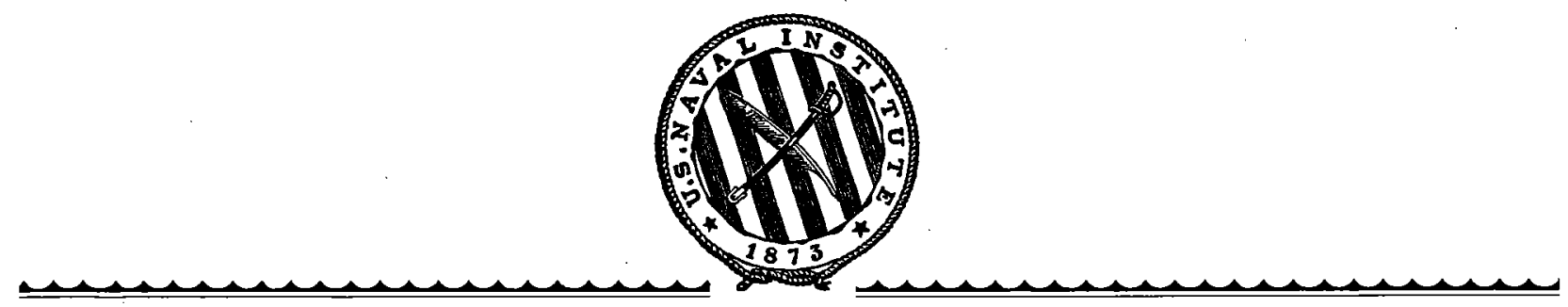

UNITED STATES NAVAL INSTITUTE

ANNAPOLIS, MARYLAND

1952 